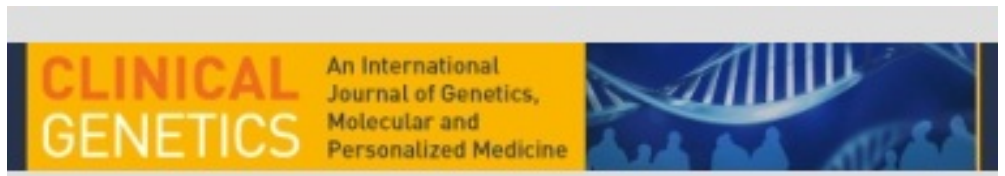

\title{
MITOCHONDRIAL DNA PATHOGENIC MUTATIONS IN MULTIPLE SYMMETRIC LIPOMATOSIS
}

\begin{tabular}{|c|c|}
\hline Journal: & Clinical Genetics \\
\hline Manuscript ID & CGE-00974-2019.R1 \\
\hline Manuscript Type: & Short Report \\
\hline $\begin{array}{r}\text { Date Submitted by the } \\
\text { Author: }\end{array}$ & $\mathrm{n} / \mathrm{a}$ \\
\hline Complete List of Authors: & $\begin{array}{l}\text { López-Gallardo, Esther; Universidad de Zaragoza i CIBERER, Bioquímica } \\
\text { y Biología Molecular y Celular } \\
\text { Cammarata-Scalisi, Francisco; University of Los Andes, Department of } \\
\text { Pediatrics } \\
\text { Emperador, Sonia; Universidad de Zaragoza i CIBERER, Bioquímica y } \\
\text { Biología Molecular y Celular } \\
\text { Hernández-Ainsa, Carmen; Universidad de Zaragoza, Bioquímica, } \\
\text { Biología Molecular y Celular } \\
\text { Habbane, Mouna; Universidad de Zaragoza, Bioquímica, Biología } \\
\text { Molecular y Celular } \\
\text { Vela-Sebastián, Ana; Universidad de Zaragoza, Bioquímica, Biología } \\
\text { Molecular y Celular } \\
\text { Bayona-Bafaluy, M.Pilar; Universidad de Zaragoza, Bioquímica, Biología } \\
\text { Molecular y Celular } \\
\text { Montoya, Julio; University of Zaragoza, Department of Biochemistry, } \\
\text { Molecular Biology } \\
\text { Ruiz-Pesini, Eduardo; Universidad de Zaragoza, Bioquímica, Biología } \\
\text { Molecular y Celular }\end{array}$ \\
\hline Key Words: & $\begin{array}{l}\text { Mitochondrial DNA mutation, Multiple symmetric lipomatosis, } \\
\text { Dermatologic manifestations, Erythema, Hyperkeratosis }\end{array}$ \\
\hline
\end{tabular}

\section{SCHOLARONE




\section{SHORT REPORT}

\section{MITOCHONDRIAL DNA PATHOGENIC MUTATIONS IN MULTIPLE SYMMETRIC LIPOMATOSIS}

SHORT RUNNING TITLE: A new mtDNA mutation causing MSL

Ester López-Gallardo 1,2,3, Francisco Cammarata-Scalisi ${ }^{4}$, Sonia Emperador 1,2,3, Carmen Hernández-Ainsa ${ }^{1,2}$, Mouna Habbane ${ }^{1,5}$, Ana Vela-Sebastián ${ }^{1}$, M.Pilar Bayona-Bafaluy 1,2,3, Julio Montoya 1,2,3,\#, Eduardo Ruiz-Pesini 1,2,3,6,\#,, .

${ }^{1}$ Departamento de Bioquímica, Biología Molecular y Celular; Universidad de Zaragoza. Zaragoza, Spain. ${ }^{2}$ Instituto de Investigación Sanitaria (IIS) de Aragón. Zaragoza, Spain. ${ }^{3}$ Centro de Investigaciones Biomédicas en Red de Enfermedades Raras (CIBERER). Spain. ${ }^{4}$ Unidad de Genética Médica; Departamento de Puericultura y Pediatría; Universidad de Los Andes. Mérida, Venezuela. ${ }^{5}$ Faculté des Sciences Ben M'Sik; Université Hassan II. Casablanca, Morocco. ${ }^{6}$ Fundación ARAID. Zaragoza, Spain.

\# These authors have equally contributed.

* Correspondence: Eduardo Ruiz-Pesini. Departamento de Bioquímica, Biología Molecular y Celular; Universidad de Zaragoza. C/ Miguel Servet, 177. 50013-Zaragoza, Spain. Phone: 34-976761646. Fax: 34-976761612. Email: eduruiz@unizar.es

\section{ACKNOWLEDGMENTS}

We would like to thank Santiago Morales for his assistance with figures.

This work was supported by grants from Instituto de Salud Carlos III [FISPI17/00021 and PI17/00166]; Fundación Mutua Madrileña MMA17/01; Precipita-FECYT crowdfunding program (PR194); Gobierno de Aragón (Grupos Consolidados B33_17R) and FEDER 2014-2020 "Construyendo Europa desde Aragón"; and Asociación de Enfermos de Patología Mitocondrial (AEPMI). The CIBERER is an initiative of the ISCIII.

\section{CONFLICT OF INTEREST}

The authors declare no conflict of interest.

\section{DATA AVAILABILITY STATEMENT}

Data available upon request. 


\begin{abstract}
The frequency of dermatological manifestations in diseases due to mitochondrial DNA mutations is not well known, although multiple symmetric lipomatosis has been repeatedly associated to mitochondrial DNA mutations. Here, we present a patient suffering from multiple symmetric lipomatosis and other skin signs. We found a new mitochondrial DNA mutation, m.8357T $>C$, in the tRNALys-coding gene and, using a cybrid approach, confirmed its pathogenicity. A meta-analysis of the dermatological signs of the patient shows that they are not common in patients with confirmed mitochondrial DNA mutations and suggests that, in these cases, lipomatosis is not related to the oxidative phosphorylation dysfunction, but to an alteration of an additional function associated to particular mitochondrial tRNAs.
\end{abstract}

\title{
KEYWORDS
}

Mitochondrial DNA mutation; multiple symmetric lipomatosis; erythema; hyperkeratosis; dermatologic manifestations. 


\section{INTRODUCTION}

Several key components of the oxidative phosphorylation (OXPHOS) system, the main biochemical pathway for energy production, are coded in the mitochondrial DNA (mtDNA). In OXPHOS disorders due to mtDNA pathological mutations, the most affected tissues are usually those with the highest energy requirements. Cultured dermal fibroblasts are frequently used for diagnosing mitochondrial diseases due to mtDNA mutations, because OXPHOS defects are detectable in these cells ${ }^{1}$. However, OXPHOS disorders are not normally accompanied by obvious skin manifestations ${ }^{2}$.

Here, we describe a patient with multiple symmetric lipomatosis (MSL), a rare disease primarily involving adipose tissue and characterized by the presence of not encapsulated fat masses, symmetrically disposed at characteristic body sites (neck, trunk, proximal parts of upper and lower limbs). The patient also showed other skin signs. We found a novel mutation in his mtDNA and confirmed its pathogenicity. Then, we review the literature on dermatologic manifestations in patients with confirmed mtDNA pathological mutations.

\section{MATERIALS AND METHODS}

DNA extraction, mtDNA sequencing, nuclear DNA (nDNA) genetic fingerprint, cybrids construction and analyses were performed as previously reported ${ }^{3,4}$.

\section{RESULTS}

\section{Case report}

We described previously the case of a 37-year-old male suffering from MSL (Figure $1 \mathrm{~A}, \mathrm{~B})^{5}$. At the age of 9 -year-old, he presented with erythematous-scaly and pruritic plaques on the face, forearms and the palms of both hands. Lesions on the palms were repeated at 17 and 37-year-old. The skin was dry with hyperkeratosis on both hands with predominance of palms. Now, at the age of 47-year-old, desquamative lesions in right thumb and index are appreciated (Figure 1C). The patient (III-1 in Figure 1D) also showed brachycephaly and facial asymmetry, degenerative discopathy, bilateral microlithiasis, sporadic elevation of blood pressure, hyperuricemia and mixed dyslipidemia. No neurological abnormalities or important developmental problems were reported.

The mother of the proband (II-1 in Figure 1D) presented with lipoma at the abdominal level $(16 \times 12 \mathrm{~cm})$ and in the left shoulder $(9 \times 7 \mathrm{~cm})$. She also suffered from osteoarthritis at the cervical level, a herniated disc at L4-L5 and controlled arterial hypertension. A maternal half sister (III-2) presented lipoma type lesions at the abdominal level and the maternal half brother (III-3), from a third father, was healthy. Four paternal half sibs from two different mothers were also healthy (Figure 1D).

Ethical approval for this study was obtained from involved Institutional Review Boards. Written informed consent from the patient was also obtained.

\section{mtDNA analysis}

mtDNA sequencing showed an $\mathrm{m} .8357 \mathrm{~T}>\mathrm{C}$ heteroplasmic transition in the MT-TK gene coding for the tRNA ${ }^{\text {Lys }}$ (Figure 2A). The mutation percentage was 53 and $65 \%$ in two different blood samples from the patient (III-1 in Figure 1D), and 43 and $38 \%$ in blood samples of his mother (II-1) and half maternal sister (III-2), respectively (Figure 2B). This 
mutation has not been previously found in 49,135 human mtDNA sequences (GenBank, accessed October $31^{\text {st }}$ 2019). The change breaks a Watson-Crick base pair in the tRNA ${ }^{\text {Lys }}$ acceptor stem (Figure 2C), which is found in 112 out of 114 mammal species (http://mamit-tRNA.u-strasbg.fr/). According to MitoTIP ${ }^{6}$, an in silico tool for predicting pathogenicity of novel mtDNA tRNA variants, m.8357T $>C$ would be possibly pathologic.

\section{Confirmation of pathogenicity by the use of cybrid cell lines}

To confirm the pathogenicity of the mutation, we generated cybrids by fusion of osteosarcoma-143B cells with no mtDNA ( $\mathrm{rho}^{0}$ cells) and platelets from the patient or controls. Since platelets contain mitochondria and mtDNA but not nucleus or nDNA, the fusion allows the transfer of the mtDNA to a common nuclear background. The resulting cybrid cell lines share their nDNA but differ in their mtDNA. Therefore, phenotypic differences among them will be due to the mtDNA that they harbor. We built three different cybrids: one with the $\mathrm{m} .8357 \mathrm{~T}>\mathrm{C}$ mutation (O8357) of the patient; one positive control harboring an already confirmed tRNAlys pathological mutation, m.8344A>G (08344); and one negative control with no pathological mutations (Owt).

First of all, we confirmed that all the three cybrids had the same nDNA. Fifteen out of 16 short tandem repeats (STRs) were shared in these cybrids (including 8 out of the 9 STR markers reported in the American Type Culture Collection for the osteosarcoma-143B cell line), thus confirming the nDNA homogeneity. Owt and 08344 cybrids had gained a new allele for the CSF1PO marker (12 and 13 versus only 12). We next confirmed the mtDNA genetic background in the cybrids (GenBank MN095205, MN095206, and MN095207 for Owt, O8344 and O8357, respectively). The 08357 cybrid was homoplasmic for the m.8357T>C mutation and the 08344 was heteroplasmic $(55 \%)$ for the $m .8344 A>G$ mutation (Figure $3 \mathrm{~A}$ ).

The 08357 cybrid showed reduced growth rate, both in glucose and galactose media, when compared with the Owt cybrid (Figure 3B). Moreover, like for the 08344 cybrid, the endogenous, leak and uncoupled oxygen consumption were significantly lower in 08357 cells (Figure 3C). The specific activity and quantity of respiratory complex IV (CIV), and p.MT-CO1 subunit levels from CIV were also significantly reduced in both cybrids when compared with the control cybrid (Figure 3D-F).

\section{Literature meta-analysis}

A review of the literature searching for the skin manifestations found in our patient, allowed us to find 49 index cases, plus 61 maternal relatives, harboring mtDNA pathological mutation and suffering from MSL (Supplementary Table): $16.3 \%$ had mtDNA deletions; $4.1 \%$ had point mutations in tRNALeu and $79.6 \%$ had point mutations in tRNA ${ }^{\text {Lys }}$.

Our patient also showed hands hyperkeratosis mainly in the palms. This sign was also found in four pedigrees, harboring the m.7445A $>\mathrm{G}$ mutation that affects the processing of tRNA ${ }^{\text {Ser }}$ showing hyperkeratosis as a sign of a keratoderma palmoplantar and deafness syndrome ${ }^{7-10}$. Hyperkeratosis was also described in a patient with MELAS syndrome harboring an m.3243A $>\mathrm{G}$ mutation in the tRNA ${ }^{\text {Leu }}{ }^{11}$. Regarding the erythematous-scaly and pruritic plaques, we only found two previous patients with mtDNA pathological mutations and showing these plaques. Both patients harbored the m.3243A>G mutation in the tRNA ${ }^{\text {Leu }} 11,12$.

\section{DISCUSSION}


Our results strongly support that the new maternally transmitted m.8357T $>C$ transition is the etiologic factor for the MSL of this patient. This is sustained by the fact that this change was not previously found in a large collection of mtDNA sequences, it was heteroplasmic and broke a conserved Watson-Crick base pair in the base of the tRNA ${ }^{\text {Lys }}$ acceptor stem. Moreover, when the patient's mtDNA was transferred to a rho ${ }^{0}$ cell line, the OXPHOS defect was also transmitted to the cybrids, in a similar way to other already confirmed tRNA ${ }^{L y s}$ pathological mutations ${ }^{13,14}$. Finally, lipomas segregated in the pedigree along with the mutation.

The frequency of skin abnormalities in mtDNA disorders is not known ${ }^{15}$, possibly because they are not generally reported in the description of these pathologies ${ }^{2}$. Interestingly, two associations between mtDNA mutations and skin manifestations have been repeatedly described: $m .7445 A>G$ mutation and keratoderma palmoplantar; and mutations in the MT-TK gene and MSL. However, our meta-analysis and other studies suggest that skin anomalies are not frequent in patients with confirmed mtDNA mutations 16 .

Thus, MSL could not due to the OXPHOS dysfunction originated by a defect in the mitochondrial translation, but to the alteration of an additional function associated to these particular tRNAs ${ }^{17}$. In this sense, it has been suggested that MSL could be the result of a disorder of proliferation and differentiation of brown adipose tissue (BAT) cells ${ }^{18}$. The BAT-specific UCP1 mRNA is expressed in lipomas from MSL patients with the m.8344A $>\mathrm{G}$ mutation ${ }^{19}$. This mutation is associated to increased mitophagy 20 that promotes the release of mitochondrial tRNA ${ }^{\text {Lys }}$ molecules. Once in the cytoplasm tRNA ${ }^{\text {Lys }}$ interacts with the cytosolic YBX1 protein ${ }^{21}$. YBX1 cooperates with EWS protein and both activate the transcription of Bmp7 ${ }^{22}$, a critical early brown adipogenic factor. Since not all patients harboring tRNA ${ }^{\text {Lys }}$ mutations develop lipomas, another factor must be also involved in the process.

\section{REFERENCES}

1. Saada A. Mitochondria: mitochondrial OXPHOS (dys) function ex vivo--the use of primary fibroblasts. Int J Biochem Cell Biol. 2014;48:60-65.

2. Feichtinger RG, Sperl W, Bauer JW, Kofler B. Mitochondrial dysfunction: a neglected component of skin diseases. Exp Dermatol. 2014;23(9):607-614.

3. Lopez-Gallardo E, Emperador S, Solano A, et al. Expanding the clinical phenotypes of MT-ATP6 mutations. Hum Mol Genet. 2014;23(23):6191-6200.

4. Emperador S, Vidal M, Hernandez-Ainsa C, et al. The decrease in mitochondrial DNA mutation load parallels visual recovery in a Leber hereditary optic neuropathy patient. Front Neurosci. 2018;12:61.

5. Cammarata-Scalisi F, Sánchez Flores R, Araujo Ramírez J. Clínica y arte de la lipomatosis simétrica benigna. Enfermedad de Madelung. Piel. 2009;24(8):419-421.

6. Sonney S, Leipzig J, Lott MT, et al. Predicting the pathogenicity of novel variants in mitochondrial tRNA with MitoTIP. PLoS Comput Biol. 2017;13(12):e1005867.

7. Hatamochi A, Nakagawa S, Ueki H, Miyoshi K, luchi I. Diffuse palmoplantar keratoderma with deafness. Arch Dermatol. 1982;118(8):605-607.

8. Sevior KB, Hatamochi A, Stewart IA, et al. Mitochondrial A7445G mutation in two pedigrees with palmoplantar keratoderma and deafness. Am J Med Genet. 1998;75(2):179-185.

9. Martin L, Toutain A, Guillen C, et al. Inherited palmoplantar keratoderma and sensorineural deafness associated with $A 7445 G$ point mutation in the mitochondrial genome. Br J Dermatol. 2000;143(4):876-883. 
10. Caria $\mathrm{H}$, Matos $\mathrm{T}$, Oliveira-Soares $\mathrm{R}$, et al. A7445G mtDNA mutation present in a Portuguese family exhibiting hereditary deafness and palmoplantar keratoderma. $J$ Eur Acad Dermatol Venereol. 2005;19(4):455-458.

11. Carmi E, Defossez C, Morin G, et al. MELAS syndrome (mitochondrial encephalopathy with lactic acidosis and stroke-like episodes. Ann Dermatol Venereol. 2001;128(10 Pt 1):1031-1035.

12. Kubota Y, Ishii T, Sugihara H, Goto Y, Mizoguchi M. Skin manifestations of a patient with mitochondrial encephalomyopathy with lactic acidosis and strokelike episodes (MELAS syndrome). J Am Acad Dermatol. 1999;41(3 Pt 1):469-473.

13. Chomyn A, Meola G, Bresolin N, Lai ST, Scarlato G, Attardi G. In vitro genetic transfer of protein synthesis and respiration defects to mitochondrial DNA-less cells with myopathy-patient mitochondria. Mol Cell Biol. 1991;11(4):2236-2244.

14. Bornstein B, Mas JA, Patrono C, et al. Comparative analysis of the pathogenic mechanisms associated with the G8363A and A8296G mutations in the mitochondrial tRNA(Lys) gene. Biochem J. 2005;387(Pt 3):773-778.

15. Flynn MK, Wee SA, Lane AT. Skin manifestations of mitochondrial DNA syndromes: case report and review. J Am Acad Dermatol. 1998;39(5 Pt 2):819-823.

16. Musumeci O, Barca E, Lamperti C, et al. Lipomatosis Incidence and Characteristics in an Italian Cohort of Mitochondrial Patients. Frontiers in neurology. 2019;10:160.

17. Larsson NG, Tulinius MH, Holme E, Oldfors A. Pathogenetic aspects of the A8344G mutation of mitochondrial DNA associated with MERRF syndrome and multiple symmetric lipomas. Muscle Nerve Suppl. 1995;3:S102-106.

18. Enzi G, Busetto L, Sergi G, et al. Multiple symmetric lipomatosis: a rare disease and its possible links to brown adipose tissue. Nutr Metab Cardiovasc Dis. 2015;25(4):347-353.

19. Plummer C, Spring PJ, Marotta R, et al. Multiple symmetrical lipomatosis--a mitochondrial disorder of brown fat. Mitochondrion. 2013;13(4):269-276.

20. De la Mata M, Garrido-Maraver J, Cotan D, et al. Recovery of MERRF fibroblasts and cybrids pathophysiology by coenzyme Q10. Neurotherapeutics. 2012;9(2):446463.

21. Jady BE, Ketele A, Kiss T. Dynamic association of human mRNP proteins with mitochondrial tRNAs in the cytosol. RNA. 2018;24(12):1706-1720.

22. Park JH, Kang HJ, Kang SI, et al. A multifunctional protein, EWS, is essential for early brown fat lineage determination. Dev Cell. 2013;26(4):393-404.

\section{FIGURE LEGENDS}

Figure 1. Clinical characteristics of the patient. A) Posterior view of the neck and shoulders with increased volume due to lipomas. B) Computational tomography of the neck (sagittal section) showing a space-occupying lesion hypodense with well-defined edges in relation to fat content. C) Desquamative, dirty looking lesion on right thumb. D) Pedigree. III-1 is the proband. The mutation percentage in blood $(B)$ is indicated.

Figure 2. m.8357T $>C$ mutation in the mtDNA. A) Electropherogram of a segment of the patient's mtDNA sequence showing the heteroplasmic m.8357T $>C$ transition. B) RFLP gel showing the mutation load in blood from the patient (P1 and P2), the mother (M) and the half-sister (HS). A, amplicon. C-, negative control. C) Secondary structure of the mitochondrial tRNAlys. The mutated position is indicated. 
Figure 3. Biochemical characterization of the cybrid cell lines. A) RFLP gel confirming the presence of the mtDNA pathological mutations $m .8344 A>G$ and $m .8357 T>C$ in the respective cell line. $M$, molecular weight marker. $A$, amplicon. B) Growing curves in glucose or galactose media. C) Oxygen consumption. E, endogenous respiration; L, leaking respiration; and $U$, uncoupled respiration. White, grey and black bars represent Owt, O8344 and 08357 cybrids, respectively. *,$p<0.05$ (vs Owt). D) Respiratory complex IV (CIV) specific activity (s.a.) normalized by citrate synthase (CS) s.a. E) CIV quantity (q.) normalized by CS s.a. F) Western blot showing the amount of the mtDNA-encoded p.MTC01 subunit from CIV. The levels of the nDNA-encoded SDHA subunit from respiratory complex II (CII) have been used to normalize. 

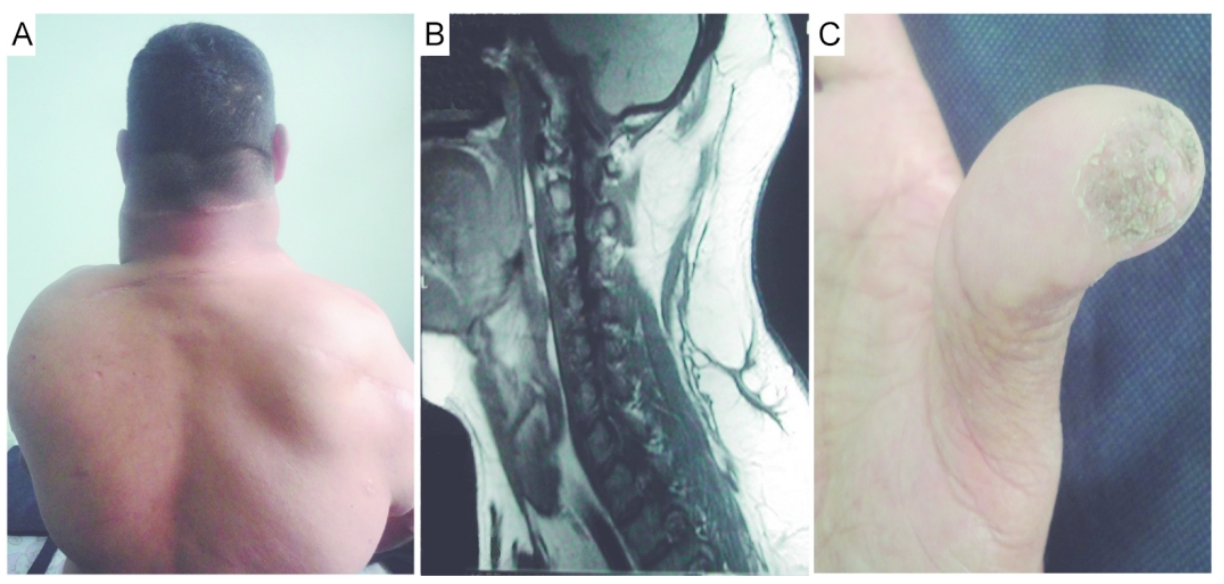

D

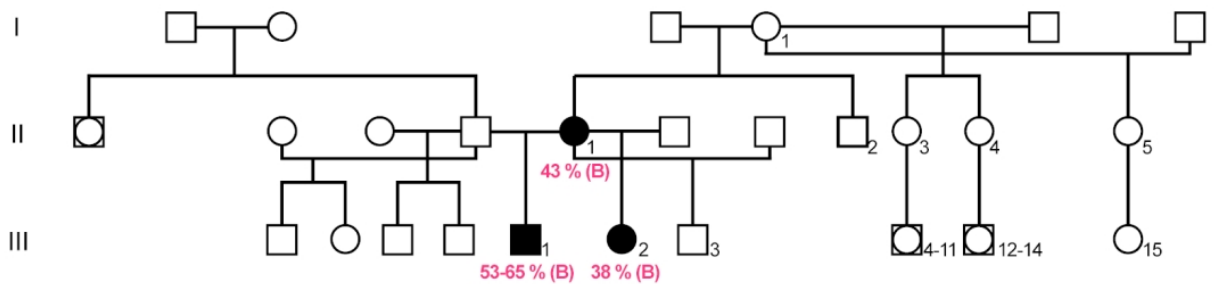

Figure 1. Clinical characteristics of the patient. A) Posterior view of the neck and shoulders with increased volume due to lipomas. B) Computational tomography of the neck (sagittal section) showing a spaceoccupying lesion hypodense with well-defined edges in relation to fat content. C) Desquamative, dirty looking lesion on right thumb. D) Pedigree. III-1 is the proband. The mutation percentage in blood (B) is indicated. 
A

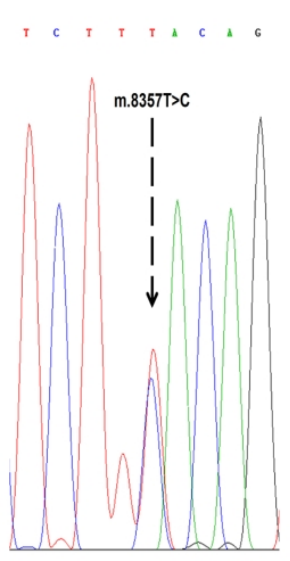

B

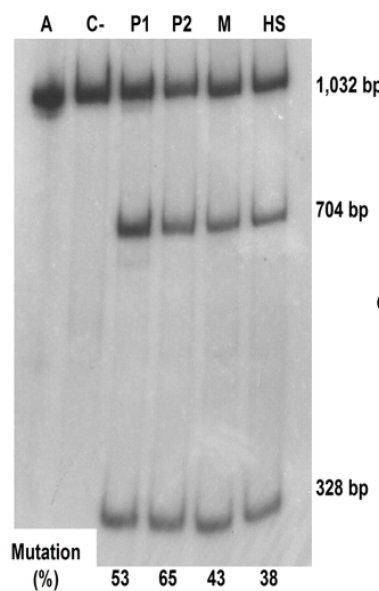

C

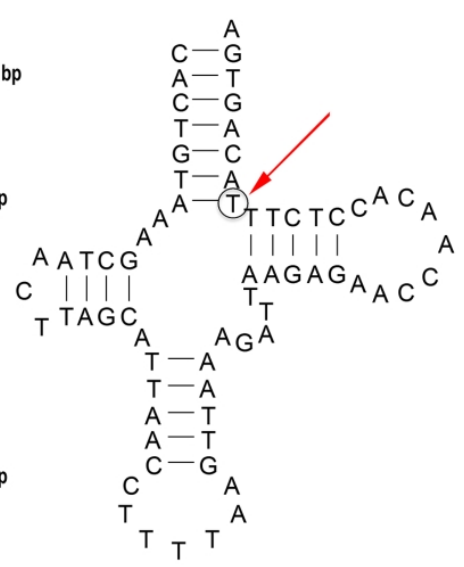

Figure 2. m.8357T>C mutation in the mtDNA. A) Electropherogram of a segment of the patient's mtDNA sequence showing the heteroplasmic m.8357T $>C$ transition. B) RFLP gel showing the mutation load in blood from the patient (P1 and P2), the mother (M) and the half-sister (HS). A, amplicon. C-, negative control. C) Secondary structure of the mitochondrial tRNAlys. The mutated position is indicated. 


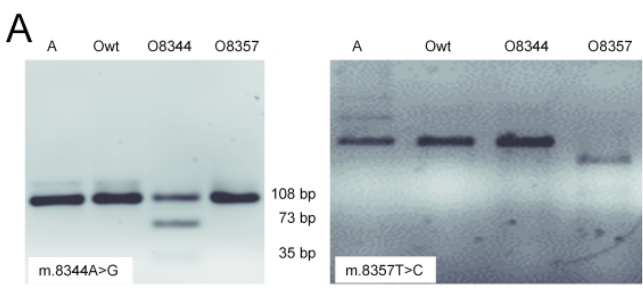

B
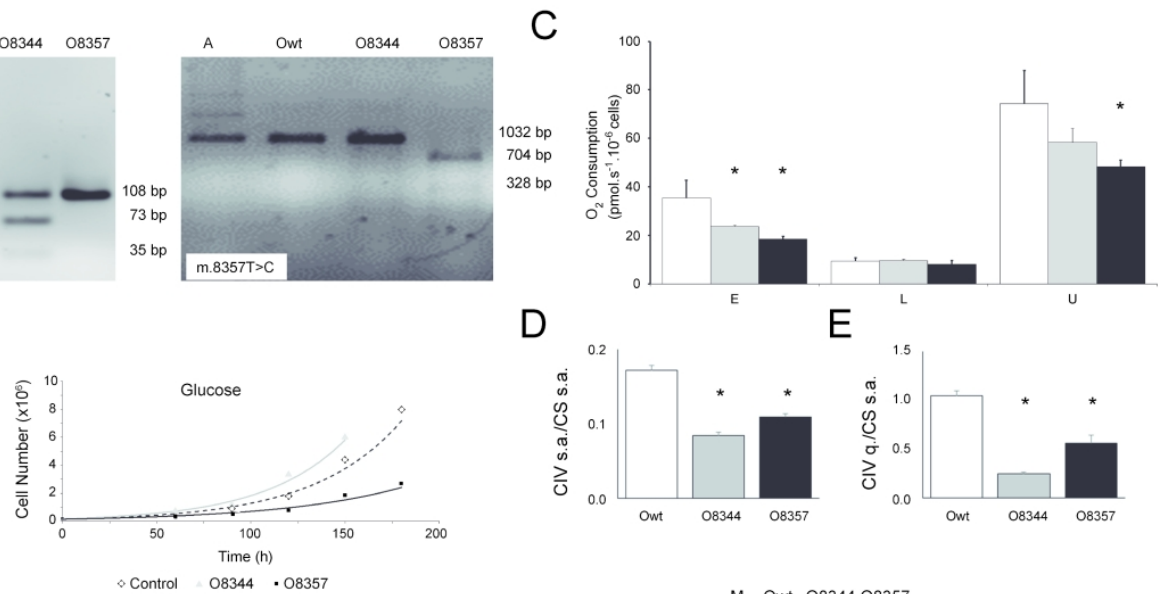

D
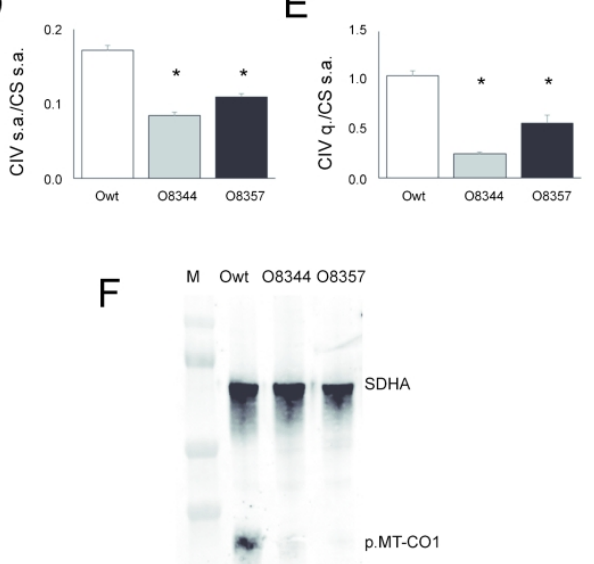

Figure 3. Biochemical characterization of the cybrid cell lines. A) RFLP gel confirming the presence of the mtDNA pathological mutations m.8344A $>\mathrm{G}$ and $\mathrm{m} .8357 \mathrm{~T}>\mathrm{C}$ in the respective cell line. $\mathrm{M}$, molecular weight marker. A, amplicon. B) Growing curves in glucose or galactose media. C) Oxygen consumption. $E$, endogenous respiration; $L$, leaking respiration; and $U$, uncoupled respiration. White, grey and black bars represent Owt, 08344 and 08357 cybrids, respectively. *, $\mathrm{p}<0.05$ (vs Owt). D) Respiratory complex IV (CIV) specific activity (s.a.) normalized by citrate synthase (CS) s.a. E) CIV quantity (q.) normalized by CS s.a. F) Western blot showing the amount of the mtDNA-encoded p.MT-CO1 subunit from CIV. The levels of the nDNA-encoded SDHA subunit from respiratory complex II (CII) have been used to normalize. 


\begin{tabular}{|c|c|c|}
\hline $\begin{array}{l}\text { Probands } \\
+ \text { Relatives }\end{array}$ & Mutation & References \\
\hline $2+1$ & $\mathrm{~m} .8344 \mathrm{~A}>\mathrm{G}(2)$ & $1-4$ \\
\hline $1+1$ & $\mathrm{~m} .8344 \mathrm{~A}>\mathrm{G}(1)$ & 5,6 \\
\hline 4 & $m .8344 A>G(3)+M D(1)$ & 7,8 \\
\hline 1 & $\mathrm{MD}(1)$ & 9,10 \\
\hline 1 & $\mathrm{~m} .8344 \mathrm{~A}>\mathrm{G}(1)$ & 11 \\
\hline $1+8$ & $\mathrm{~m} .8344 \mathrm{~A}>\mathrm{G}(1)$ & 12 \\
\hline 1 & SD (1) & 13 \\
\hline 1 & m.8363G>A (1) & 14 \\
\hline 1 & $\mathrm{~m} \cdot 3243 \mathrm{~A}>\mathrm{G}(1)$ & 15 \\
\hline 1 & $\mathrm{~m} .8344 \mathrm{~A}>\mathrm{G}(1)$ & 10,16 \\
\hline 1 & m.3264T>C (1) & $17 \mathrm{NCP}$ \\
\hline $1+17$ & $\mathrm{~m} .8344 \mathrm{~A}>\mathrm{G}(1)$ & 18 \\
\hline $1+7$ & m.8344A>G (1) & $19-21$ \\
\hline $1+2$ & $\mathrm{~m} .8363 \mathrm{G}>\mathrm{A}(1)$ & 22 \\
\hline $1+?$ & $\mathrm{MD}(1)$ & 23 \\
\hline 1 & $\mathrm{~m} .8344 \mathrm{~A}>\mathrm{G}(1)$ & 24 \\
\hline $2+2$ & $\mathrm{~m} .8344 \mathrm{~A}>\mathrm{G}(2)$ & 25 \\
\hline 1 & SD (1) & 26 \\
\hline 1 & m.8344A>G (1) & 27 \\
\hline 3 & SD (3) & 28 \\
\hline 1 & $\mathrm{~m} \cdot 3271 \mathrm{~T}>\mathrm{C}(1)$ & 29 only one small lipoma \\
\hline 2 & $\mathrm{~m} .8344 \mathrm{~A}>\mathrm{G}(2)$ & 30 \\
\hline 2 & $\mathrm{~m} .8344 \mathrm{~A}>\mathrm{G}(2)$ & 31 \\
\hline $1+2$ & $\mathrm{~m} .8363 \mathrm{G}>\mathrm{A}(1)$ & 21,32 \\
\hline 1 & $\mathrm{~m} \cdot 3243 \mathrm{~A}>\mathrm{G}(1)$ & ${ }^{33}$ Mutation $\% \leq 0.102$ \\
\hline 1 & $\mathrm{~m} .8344 \mathrm{~A}>\mathrm{G}(1)$ & 21 \\
\hline 1 & $\mathrm{~m} .8344 \mathrm{~A}>\mathrm{G}(1)$ & 34 \\
\hline 1 & $\mathrm{~m} .8344 \mathrm{~A}>\mathrm{G}(1)$ & 35 \\
\hline 1 & $\mathrm{~m} .8344 \mathrm{~A}>\mathrm{G}(1)$ & 36 \\
\hline 1 & $\mathrm{~m} .4302 \mathrm{~A}>\mathrm{G}(1)$ & ${ }^{37} \mathrm{NCP}$ \\
\hline 1 & $\mathrm{~m} .8344 \mathrm{~A}>\mathrm{G}(1)$ & 30,38 \\
\hline $1+6$ & $\mathrm{~m} .8344 \mathrm{~A}>\mathrm{G}(1)$ & 39 \\
\hline $4+3$ & $\mathrm{~m} .8344 \mathrm{~A}>\mathrm{G}(4)$ & 40 \\
\hline $1+1$ & $\mathrm{~m} .8344 \mathrm{~A}>\mathrm{G}(1)$ & 41 \\
\hline 1 & $\mathrm{~m} .8344 \mathrm{~A}>\mathrm{G}+\mathrm{m} \cdot 14484 \mathrm{~T}>\mathrm{C}(1)$ & 42 \\
\hline 1 & $\mathrm{~m} .8344 \mathrm{~A}>\mathrm{G}(1)$ & 43 \\
\hline $2+2$ & $m .8344 A>G(1)+m .8363 G>A(1)$ & 44 \\
\hline 1 & $\mathrm{~m} .8344 \mathrm{~A}>\mathrm{G}(1)$ & 45 \\
\hline $1+9$ & $\mathrm{~m} .8344 \mathrm{~A}>\mathrm{G}(1)$ & 46 \\
\hline
\end{tabular}

Supplemental Table. Multiple symmetric lipomatosis and mitochondrial DNA mutations. MD, multiple deletions. SD, single deletion. NCP, Non-confirmed pathogenicity.

19 probands +3 relatives are reported in ${ }^{47}$ but they do not clarify whether some of them have been previously described. 


\section{References}

1. Berkovic SF, Carpenter S, Evans A, et al. Myoclonus epilepsy and ragged-red fibres (MERRF). 1. A clinical, pathological, biochemical, magnetic resonance spectrographic and positron emission tomographic study. Brain. 1989;112 ( Pt 5):1231-1260.

2. Shoffner JM, Lott MT, Lezza AM, Seibel P, Ballinger SW, Wallace DC. Myoclonic epilepsy and ragged-red fiber disease (MERRF) is associated with a mitochondrial DNA tRNA(Lys) mutation. Cell. 1990;61(6):931-937.

3. Berkovic SF, Andermann F, Shoubridge EA, et al. Mitochondrial dysfunction in multiple symmetrical lipomatosis. Ann Neurol. 1991;29(5):566-569.

4. Berkovic SF, Shoubridge EA, Andermann F, Andermann E, Carpenter S, Karpati G. Clinical spectrum of mitochondrial DNA mutation at base pair 8344. Lancet. 1991;338(8764):457.

5. Larsson NG, Tulinius MH, Holme E, et al. Segregation and manifestations of the mtDNA tRNA(Lys) A-->G(8344) mutation of myoclonus epilepsy and ragged-red fibers (MERRF) syndrome. Am J Hum Genet. 1992;51(6):1201-1212.

6. Holme E, Larsson NG, Oldfors A, Tulinius M, Sahlin P, Stenman G. Multiple symmetric lipomas with high levels of mtDNA with the tRNA(Lys) A-->G(8344) mutation as the only manifestation of disease in a carrier of myoclonus epilepsy and ragged-red fibers (MERRF) syndrome. Am J Hum Genet. 1993;52(3):551-556.

7. Silvestri G, Ciafaloni E, Santorelli FM, et al. Clinical features associated with the A-$>\mathrm{G}$ transition at nucleotide 8344 of mtDNA ("MERRF mutation"). Neurology. 1993;43(6):1200-1206.

8. Suomalainen A, Ciafaloni E, Koga Y, Peltonen L, DiMauro S, Schon EA. Use of single strand conformation polymorphism analysis to detect point mutations in human mitochondrial DNA. J Neurol Sci. 1992;111(2):222-226.

9. Klopstock T, Naumann M, Schalke B, et al. Multiple symmetric lipomatosis: abnormalities in complex IV and multiple deletions in mitochondrial DNA. Neurology. 1994;44(5):862-866.

10. Klopstock T, Naumann M, Seibel P, Shalke B, Reiners K, Reichmann H. Mitochondrial DNA mutations in multiple symmetric lipomatosis. Mol Cell Biochem. 1997;174(1-2):271-275.

11. Calabresi PA, Silvestri G, DiMauro S, Griggs RC. Ekbom's syndrome: lipomas, ataxia, and neuropathy with MERRF. Muscle Nerve. 1994;17(8):943-945.

12. Traff J, Holme E, Ekbom K, Nilsson BY. Ekbom's syndrome of photomyoclonus, cerebellar ataxia and cervical lipoma is associated with the tRNA(Lys) A8344G mutation in mitochondrial DNA. Acta Neurol Scand. 1995;92(5):394-397.

13. Campos Y, Martin MA, Navarro C, Gordo P, Arenas J. Single large-scale mitochondrial DNA deletion in a patient with mitochondrial myopathy associated with multiple symmetric lipomatosis. Neurology. 1996;47(4):1012-1014.

14. Santorelli FM, Mak SC, El-Schahawi M, et al. Maternally inherited cardiomyopathy and hearing loss associated with a novel mutation in the mitochondrial tRNA(Lys) gene (G8363A). Am J Hum Genet. 1996;58(5):933-939.

15. Fabrizi GM, Cardaioli E, Grieco GS, et al. The A to $G$ transition at nt 3243 of the mitochondrial tRNALeu(UUR) may cause an MERRF syndrome. $J$ Neurol Neurosurg Psychiatry. 1996;61(1):47-51.

16. Naumann M, Kiefer R, Toyka KV, Sommer C, Seibel P, Reichmann H. Mitochondrial dysfunction with myoclonus epilepsy and ragged-red fibers point 
mutation in nerve, muscle, and adipose tissue of a patient with multiple symmetric lipomatosis. Muscle Nerve. 1997;20(7):833-839.

17. Suzuki Y, Suzuki S, Hinokio Y, et al. Diabetes associated with a novel 3264 mitochondrial tRNA(Leu)(UUR) mutation. Diabetes Care. 1997;20(7):1138-1140.

18. Austin SA, Vriesendorp FJ, Thandroyen FT, Hecht JT, Jones OT, Johns DR. Expanding the phenotype of the 8344 transfer RNAlysine mitochondrial DNA mutation. Neurology. 1998;51(5):1447-1450.

19. Gamez J, Playan A, Andreu AL, et al. Familial multiple symmetric lipomatosis associated with the A8344G mutation of mitochondrial DNA. Neurology. 1998;51(1):258-260.

20. Tanji K, Gamez J, Cervera C, et al. The A8344G mutation in mitochondrial DNA associated with stroke-like episodes and gastrointestinal dysfunction. Acta Neuropathol. 2003;105(1):69-75.

21. Guallar JP, Vila MR, Lopez-Gallardo E, et al. Altered expression of master regulatory genes of adipogenesis in lipomas from patients bearing tRNA(Lys) point mutations in mitochondrial DNA. Mol Genet Metab. 2006;89(3):283-285.

22. Casali C, Fabrizi GM, Santorelli FM, et al. Mitochondrial G8363A mutation presenting as cerebellar ataxia and lipomas in an Italian family. Neurology. 1999;52(5):1103-1104.

23. Mancuso M, Bianchi MC, Santorelli FM, et al. Encephalomyopathy with multiple mitochondrial DNA deletions and multiple symmetric lipomatosis: further evidence of a possible association. J Neurol. 1999;246(12):1197-1198.

24. Coin A, Enzi G, Bussolotto M, Ceschin E, Difito M, Angelini C. Multiple symmetric lipomatosis: evidence for mitochondrial dysfunction. J Clin Neuromuscul Dis. 2000;1(3):124-130.

25. Munoz-Malaga A, Bautista J, Salazar JA, et al. Lipomatosis, proximal myopathy, and the mitochondrial 8344 mutation. A lipid storage myopathy? Muscle Nerve. 2000;23(4):538-542.

26. Siciliano G, Mancuso M, Ceravolo R, Lombardi V, ludice A, Bonuccelli U. Mitochondrial DNA rearrangements in young onset parkinsonism: two case reports. J Neurol Neurosurg Psychiatry. 2001;71(5):685-687.

27. Lee YC, Wei YH, Lirng JF, et al. Wernicke's encephalopathy in a patient with multiple symmetrical lipomatosis and the A8344G mutation of mitochondrial DNA. Eur Neurol. 2002;47(2):126-128.

28. Nisoli E, Regianini L, Briscini L, et al. Multiple symmetric lipomatosis may be the consequence of defective noradrenergic modulation of proliferation and differentiation of brown fat cells. J Pathol. 2002;198(3):378-387.

29. Suzuki Y, Tsukuda K, Taniyama M, Atsumi Y, Matsuoka K, Oka Y. Lipoma and sensory neuropathy in mitochondrial diabetes associated with tRNA mutation at position 3271. Diabetes Care. 2002;25(2):407-408.

30. Aure K, Sternberg D, Maisonobe T, et al. Myopathy-lipomatosis associated with A8344G mitochondrial DNA mutation. Rev Neurol (Paris). 2003;159(12):1163-1168.

31. Chong PS, Vucic S, Hedley-Whyte ET, Dreyer M, Cros D. Multiple symmetric lipomatosis (Madelung's disease) caused by the MERRF (A8344G) mutation: a report of two cases and review of the literature. $J$ Clin Neuromuscul Dis. 2003;5(1):1-7.

32. Pineda M, Solano A, Artuch R, et al. Peripheral neuropathy with ataxia in childhood as a result of the G8363A mutation in mitochondrial DNA. Pediatr Res. 2004;56(1):55-59.

33. Suzuki Y, Nishimaki K, Taniyama M, et al. Lipoma and opthalmoplegia in 
mitochondrial diabetes associated with small heteroplasmy level of 3243 tRNA(Leu(UUR)) mutation. Diabetes Res Clin Pract. 2004;63(3):225-229.

34. Schoffer K, Grant I. Multiple lipomas, alcoholism, and neuropathy: Madelung's disease or MERRF? Muscle Nerve. 2006;33(1):142-146.

35. Teive HA, Munhoz RP, Muzzio JA, et al. Cerebellar ataxia, myoclonus, cervical lipomas, and MERRF syndrome. Case report. Mov Disord. 2008;23(8):1191-1192.

36. Kobayashi J, Nagao M, Miyamoto K, Matsubara S. MERRF syndrome presenting with multiple symmetric lipomatosis in a Japanese patient. Intern Med. 2010;49(5):479-482.

37. Berardo A, Coku J, Kurt B, DiMauro S, Hirano M. A novel mutation in the tRNAlle gene (MTTI) affecting the variable loop in a patient with chronic progressive external ophthalmoplegia (CPEO). Neuromuscul Disord. 2010;20(3):204-206.

38. Bereziat V, Cervera P, Le Dour C, et al. LMNA mutations induce a noninflammatory fibrosis and a brown fat-like dystrophy of enlarged cervical adipose tissue. Am J Pathol. 2011;179(5):2443-2453.

39. Kazakos K, Kotsa K, Yavropoulou M, et al. Familial clustering strongly suggests that the phenotypic variation of the $8344 \mathrm{~A}>\mathrm{G}$ lys mitochondrial tRNA mutation is encoded in cis. Ann Hum Genet. 2012;76(4):296-300.

40. Plummer C, Spring PJ, Marotta R, et al. Multiple symmetrical lipomatosis--a mitochondrial disorder of brown fat. Mitochondrion. 2013;13(4):269-276.

41. Jeppesen TD, Al-Hashimi N, Duno M, Wibrand F, Andersen G, Vissing J. Mitochondrial DNA mutation load in a family with the m.8344A $>\mathrm{G}$ point mutation and lipomas: a case study. Clin Case Rep. 2017;5(12):2034-2039.

42. Lopez-Blanco R, Rojo-Sebastian A, Torregrosa-Martinez MH, Blazquez A. Beyond cervical lipomas: myoclonus, gait disorder and multisystem involvement leading to mitochondrial disease. BMJ Case Rep. 2017;2017.

43. Fekete A, Hadzsiev K, Bene J, et al. A8344G mitochondrial DNA mutation observed in two generations. Orv Hetil. 2017;158(12):468-471.

44. Carre F, Hervochon R, Foirest C, Tankere F. MERRF syndrome (myoclonic epilepsy with ragged red fibres) presenting with cervicothoracic lipomatosis. Eur Ann Otorhinolaryngol Head Neck Dis. 2019;136(2):113-114.

45. Gilson RC, Osswald S. Madelung lipomatosis presenting as a manifestation of myoclonic epilepsy with ragged red fibers (MERRF) syndrome. JAAD case reports. 2018;4(8):822-823.

46. Perera U, Kennedy BA, Hegele RA. Multiple symmetric lipomatosis (Madelung disease) in a large Canadian family with the mitochondrial MTTK c.8344A>G variant. J Investig Med High Impact Case Rep. 2018;6:2324709618802867.

47. Musumeci O, Barca E, Lamperti C, et al. Lipomatosis Incidence and Characteristics in an Italian Cohort of Mitochondrial Patients. Frontiers in neurology. 2019;10:160. 